interpreted to suggest that some informational conflict, however small, was inherent in the banal stimuli, and that a familiarity effect was observed because the informational conflict inherent in one of the two banal stimuli was resolved during its preexposure.

While it is interesting to speculate as to the basis of the unpredicted result that was observed in the present experiment, and to search for evidence in support of various interpretations of that result, speculation is little more than an exercise in a posteriori theorizing. It will be an important role of future research to first verify the reliability of this initial observation, and then proceed to examine the adequacy of the various explanations that are proposed to explain it.

\section{REFERENCES}

BERLYNE, D. E. The influence of complexity and novelty in visual figures on orienting response. Journal of Experimental Psychology, $1958,55,289-296$.

FAW, T. T., \& NUNNALLY, J. C. The effects on eye movements of complexity, novelty and affective tone. Perception \& Psychophysics, $1967,2,263-267$.

FAW, T. T., \& NUNNALLY, J. C. The familiarity effect in visual selection: Satiation or information conflict resolution? Proceedings of the American Psychological Association, 1969.

NUNNALLY, J. C., FAW, T. T., \& BASHFORD, $M$. B. The effect of degrees of incongruity on visual fixations in children and adults. Joumal of Experimental Psychology, 1969, 81, 360-364.

\section{NOTE}

1. This study was supported, in part, by Research Grant HD-03083 from the National Institute of Child Health and Human Development to the second author and, in part, by NIMH Predoctoral Fellowship No. MH39863 to the first author. The authors wish to express their thanks to Mrs. Nancy Ator and Miss Evelyn Proctor for their assistance in this experiment.

\title{
Social comparison, influence, and need achievement ${ }^{1}$
}

\author{
PATRICIA L. SHAPIRO, 2 Pennsylvania \\ State University, University Park, $P$. \\ 16802
}

The experiment tested the hypotheses that (1) Ss whose motive to approach success (Ms) is greater than their motive to avoid failure (Mf) would join influenceable groups and (2) Ss whose Mf is greater than Ms would join groups providing social comparison. The Ss whose Ms $>$ Mf chose others whose opinions differed from their own to a greater extent than $S$ s whose Mf $>$ Ms. Although the data could be viewed as supporting the hypotheses, another interpretation discussed is that $S$ s for whom Ms $>M f$ accept a broader range of views for social comparison.

Testing one aspect of Festinger's (1954) social-comparison theory, Radloff (1961) has demonstrated that Ss who lack confidence in the correctness of their opinions will affiliate for opinion evaluation. Gordon (1966) has demonstrated that confident Ss will affiliate for the purpose of influencing others, and also that high- and low-confidence Ss chose to affiliate with different sorts of groups. The low-confidence $S$ prefers affiliation with groups composed of individuals who are likely to be correct and who agree with him. Festinger (1954) maintains that such groups provide social comparison and social reality, and should increase S's confidence in his correctness. The high-confidence $S$ prefers affiliation with others who know they are likely to be incorrect and who disagree with him. Gordon argues that such groups will be seen as good targets for influence since their low probability of correctness should result in low confidence and increased persuasability.

Two lines of evidence suggest that S's degree of motivation to approach success (Ms) and to avoid failure (Mf), as defined by Atkinson (1958), will affect S's decision to seek social comparison or to attempt influence. It is predicted that Ss whose Ms $>$ Mf will attempt influence for two reasons. First, Atkinson argues that $\mathrm{Ss}$ whose Ms $>$ Mf will seek out and perform at their best in achievement situations, situations in which good performance leads to success or in which performance will be evaluated against some standard of excellence. Situations in which influence is possible seem to provide achievement opportunities, particularly since successful influence provides evidence of successful leadership, which is definitely considered an achievement in American culture. Therefore, it is predicted that Ss whose Ms > Mf will affiliate with influenceable others. Secondly, Brody (1963) has demonstrated that Ss who are high in Ms are more confident of their correctness than are those low in Ms. It will be recalled that high-confident Ss seek to influence others. It is also predicted that those whose Mf $>$ Ms will seek social comparison and social reality. First, Atkinson argues that such Ss will avoid achievement situations, and second, as Brody demonstrated, their confidence is likely to be low. To increase their confidence, they should seek a group providing social comparison and social reality.

\section{PROCEDURE ${ }^{3}$}

In the first phase of the experiment, 62 male undergraduates at The Pennsylvania State University were given the Mandler Sarason Test Anxiety questionnaire (Mandler \& Sarason, 1952) to measure Mf and the Thematic Apperception Test (TAT) to measure Ms. The neutral instructions for the TAT (Atkinson, 1958) were read. Four pictures $(4,17 \mathrm{BM}, 13 \mathrm{~B}$, and 14) were each shown for $20 \mathrm{sec}$, and Ss were given $4 \mathrm{~min}$ to write each story. The E scored these for $\mathbf{n}$ Ach after establishing a reliability of .90 with the practice stories in Atkinson (1958). The Ss were divided into four groups, designated as follows: HL-high n Ach, low TAQ $(\mathrm{N}=15)$; HH-high n Ach, high TAQ $(\mathrm{N}=16)$; LL-low n Ach, low TAQ $(\mathrm{N}=16)$; LH-low n Ach, high TAQ $(\mathrm{N}=15)$. For each test, Ss scoring at or above the median ( 0 for the TAT, 190 for the TAQ) were assigned to the $H$ groups, and the others were assigned to the $\mathrm{L}$ groups. For HL Ss, Ms $>$ Mf, and for LH Ss, Mf $>$ Ms. Since the relative strengths of $\mathrm{Mf}$ and $\mathrm{Ms}$ for $\mathrm{HH}$ and LL Ss cannot be specified, these Ss were not further tested.

In the second phase of the experiment, $E$ used an intercom to communicate with Ss who were tested one, two, or three at a time in individual, sound-deadened cubicles. The Ss were told that they would make decisions on three case studies and 
that the first two would be corrected and returned to them. E explained that the outcome of Case 3 was not yet known so this decision could not be corrected. The Ss were told they would later discuss Case 3 with other students. The case studies used were Gordon's (1965) modifications of materials devised by Hochbaum (1954). The Ss made their decisions on Cases 1 and 2 , which were then marked "correct" and returned. After Case 3, described to the Ss as the most difficult, was completed, E told Ss that because of their personality test scores (n Ach, TAQ) and their correctness on Cases 1 and 2, they had been chosen as leaders for the discussion portion of the experiment. It was explained that better discussion results when leaders choose their own group members, and $S$ s were instructed to choose 3 others from 51 Ss listed. Each of the 51 was listed as either correct or incorrect on the first two cases and a numerical value was given for his answer on Case 3. The numerical value of S's own answer was also given so that he knew how similar other answers were to his own. After $\mathrm{S}$ completed his choices, he answered questions involving his perception of his correctness and understanding of the information given to him about the members among whom he chose. He also indicated his reasons for member choice. The Ss were then debriefed and questioned about prior knowledge of the experiment and suspicion about the procedures. One HL S's data were dropped due to suspicion, and to equalize group size, one LH S's data were dropped.

\section{RESULTS}

Various checks on Ss' understanding of the information presented to them indicated adequate understanding. The Ss rated their own correctness at 14.45 on a 16.0-point scale, indicating high acceptance of the correctness manipulation. However, confidence that their third decision was correct was rated at only 9.68 on the 16.0-point scale. Average confidence was 9.44 for HL Ss and 9.92 for the LH Ss. All Ss correctly answered questions dealing with how many "correct" group members they had chosen and the degree of discrepancy between own and others' answers.

The data relevant to the two major hypotheses, that HL Ss will affiliate for the purpose of influence and that LH Ss will affiliate for social comparison, consist of Ss' choice of group members. It was predicted that $\mathrm{HL}$ Ss would choose more incorrect members than LH Ss, and that HL Ss would choose members whose opinions were less similar to their own than the LH Ss. The first prediction was not supported. Of the three members Ss chose for their discussion groups, the average number of correct members chosen by LH Ss was 2.15 and for the HL Ss, 2.07.

The degree of opinion discrepancy was analyzed in three ways. A total discrepancy score (TD) was calculated by subtracting the numerical value of S's opinion from that of each member he chose and summing the absolute values of these differences. The mean TD score for LH Ss was 19.49 , and for HL Ss, 23.30. Although in the predicted direction, the difference is not significant $(t=1.21, \mathrm{df}=26, \mathrm{p}>.20)$. A range of opinion score (RO) was obtained by determining the difference between the values of the extreme scores, including S's score, within each group. The mean RO score for LH Ss was 13.13, and for $\mathrm{HL} S s, 15.54 \quad(t=2.45, \mathrm{df}=26$, $\mathrm{p}<.05)$. Finally, a range of discrepancy score (RD) was calculated by determining, for each $S$, the difference between the opinions closest to and furthest from his own. The mean RD score for $\mathrm{HL}$ Ss was 12.04, and for LH Ss, $8.79(t=2.07$, $\mathrm{df}=26, \mathrm{p}<.05)$. The RD and RO scores support the hypothesis that HL Ss choose group members whose opinions are more discrepant from their own than do LH Ss.

Further analyses of the data indicated that the larger RD for HL Ss is primarily accounted for by their tendency to choose one member whose opinion is further from their own than do LH Ss. This conclusion was reached by determining the average differences for the LH and HL Ss between (1) each S's answer and the answer closest to his own (O-C) and (2) each S's answer and the answer furthest from his own (O-F). For HL Ss, O-C is 1.91 , for LH Ss, it is $1.53(\mathrm{t}=.54, \mathrm{df}=26, \mathrm{p}>.20)$. The O-F score for HL Ss is 13.56; for LH Ss, it is $10.70(t=2.01, d f=26, p<.10)$.

When asked why they had chosen the group members they did, both LH and HL Ss gave correctness and disagreement as the predominant answers.

\section{DISCUSSION}

The differences between the $\mathrm{LH}$ and HL groups are best interpreted as indicating that HL Ss seek a wider range of opinion for social comparison than do LH Ss. It appears that neither group is interested in influence. First, the predominant reasons both LH and HL Ss gave for their choice of group members indicate interest in social comparison. Second, both $\mathrm{LH}$ and $\mathrm{HL}$ Ss formed groups of predominately correct individuals with widely differing opinions. According to the Festinger and Gordon specifications cited earlier, these groups provide neither ideal sources of social comparison nor targets for influence. However, Thornton \& Arrowood (1966) demonstrated that $\mathrm{Ss}$ choose to compare with discrepant rather than similar scores when the former are more informative about their group standing. Similarly, the correct, disagreeing individuals in the present study may provide more information and a greater chance of accurate opinion evaluation than do correct, agreeing individuals. Finally, Singer (1966) states that people usually seek social comparison to evaluate not only a single opinion or ability, but also to obtain a general self-evaluation. Other people with dissimilar opinions appear to be useful primarily for determining accuracy. People with similar opinions may provide general self-evaluation by allowing $S$ to see what kind of people share his beliefs.

\section{REFERENCES}

ATKINSON, J. W. Towards experimental analysis of human motivation in terms of motives, expectancies, and incentives. In J. W. Atkinson (Ed.), Motives in fantasy, action and society. Princeton: Van Nostrand, 1958. Pp. 288-305.

BRODY, N. $n$ achievement, test anxiety and subjective probability of success in risk taking behavior. Joumal of Abnormal \& Social Psychology, 1963, 66, 413-418.

FESTINGER, L. A theory of social comparison processes. Human Relations, 1954, 7, 117-140.

GORDON, B. F. Influence, social comparison and affiliation. Unpublished doctoral dissertation, Columbia University, 1965.

GORDON, B. F. Influence and social comparison as motives for affiliation. In B. Latané (Ed.), Studies in social comparison. New York: Academic Press, 1966, Pp. 55-65.

HOCHBAUM, G. M. The relation between group members' self-confidence and their reactions to group pressures to uniformity. American Sociological Review, 1954, 6, 678-687.

LAMB, B. F. Social comparison, influence, and need achievement. Unpublished doctoral dissertation, The Pennsylvania State University, 1966.

MANDLER, S., \& SARASON, S. B. A study of anxiety and learning. Journal of Abnormal \& Social Psychology, 1952, 47, 166-173.

RADLOFF, R. Opinion evaluation and affiliation. Journal of Abnormal \& Social Psychology, 1961, 62, 578-585.

SINGER, J. E. Social comparison-progress and issues. In B. Latané (Ed.), Studies in social comparison. New York: Academic Press, 1966. Pp. 103-110.

THORNTON, D. A., \& ARROWOOD, A. J. Self-evaluation, self-enhancement, and the locus of social comparison. In B. Latané (Ed.) Studies in social comparison. New York: Academic Press, 1966. Pp. 40-48. NOTES

1. This report is based on a dissertation submitted in partial fulfillment of the requirements of the $\mathrm{PhD}$ degree at The Pennsylvania State University. The author is particularly indebted to her adviser, Jerome $E$. Singer, for his helpful suggestions during various stages of this project.

2. Now at the University of Hawaii.

3. Two unpublished experiments (Lamb, 1966) essentially replicated one of Gordon's (1966) procedures, but failed to replicate his results, probably due to differences in Ss backgrounds. Gordon's Ss came primarily from urban areas while the author's data came primarily from Ss from small towns and rural areas. 